\title{
$\underline{\mathbf{P}-179}$
}

\section{Synthesis of Cyclohexene Silyl Ether Peptides}

\author{
Mohd Tajudin Mohd Ali*, Siti Aisyah Aliasak and Habsah Zahari \\ Faculty of Applied Sciences, Universiti Teknologi MARA, 40450 Shah Alam, Malaysia; \\ E-mail: tajudinali@salam.uitm.edu.my
}

Peptides- bearing natural amino acids scaffolds are widespread in nature and are known to exhibit a wide array of biological activities. As part of a research endeavor in investigating the synthetic utility of enantiopure azido cyclohexene silyl ether, we hereby present an approach towards the synthesis of anti-influenza drugs, oseltamivir starting from azido cyclohexene silyl ether. The methodology proceeds via reduction of azide, followed by Boc protection of amine termini. Deprotection of Boc group and coupling reaction with natural amino acids using standard peptide coupling protocols affording cyclohexene silyl ether peptides.

Keywords: Azido cyclohexene silyl ether, oseltamivir, peptides. 